\title{
Is plane strain a valid assumption in non-cylindrical fault-cored folds?
}

\author{
J. Ryan Shackleton*, Michele L. Cooke \\ Department of Geosciences, University of Massachusetts, Amherst, 611 North Pleasant Street, Amherst, MA 01003-9297, USA
}

Received 14 June 2006; received in revised form 16 February 2007; accepted 8 March 2007

Available online 19 March 2007

\begin{abstract}
Many algorithms assume plane strain to construct, model and restore fault-cored folds. Using mechanical models that allow heterogeneous transport in three dimensions, we explore the distribution and magnitude of out-of-plane transport in plunging fault-cored anticlines and provide guidelines of where plane strain should and should not be applied. We developed a new technique of incrementing infinitesimal elastic strains to produce folds with aspect ratios similar to natural folds. Map views of displacement vectors show that in general, out-of-plane displacement is localized near the lateral fold tips. Cross-sections show that out-of-plane transport is depth dependent with out-of-plane displacement increasing toward the surface. Flexural slip surfaces compartmentalize out-of-plane transport within distinct mechanical units, with the maximum outof-plane displacement near the tops of mechanical units. Two-dimensional models with additional frictionally slipping bed contacts suggest that freely slipping contacts can approximate the deformation of many frictionally slipping contacts. We show that out-of-plane transport is significant in the simplest non-cylindrical folds, and suggest that complex non-cylindrical structures should not be modeled using plane strain exclusively. We also show that flexural slip surfaces exert a significant control on the magnitude and structural position of out-of-plane transport in our models.
\end{abstract}

(C) 2007 Elsevier Ltd. All rights reserved.

Keywords: Fault-cored folds; Fold growth; BEM models; 3d models; Plane strain; Restoration; Interlayer slip

\section{Introduction}

Analysis, restoration, and modeling of geologic faults and folds has traditionally been performed on two-dimensional cross-sections due to limited techniques for cross-section balancing and construction, as well as computational constraints on forward modeling and restoration. Many current techniques for analyzing three-dimensional models of geologic structures rely on interpolation between serial cross-sections to forward model and restore what are termed "pseudo threedimensional," or "2D-3D" geologic surfaces (Fig. 1) (e.g. Bernal and Hardy, 2002; Cristallini and Allmendinger, 2001; Epard and Groshong, 1995; Fischer and Wilkerson, 2000; Griffiths et al., 2002; Salvini and Storti, 2002). Pseudo threedimensional models are invaluable for reconstruction of

\footnotetext{
* Corresponding author. Tel.: +14135451913.

E-mail address: ryan@geo.umass.edu (J.R. Shackleton).
}

three-dimensional surfaces, but are still bound by the constraint of plane strain and therefore may neglect some inherently three-dimensional aspects of doubly plunging folds (Fig. 1). For example, a common technique for flexural slip unfolding utilizes serial transport planes to geometrically restore three-dimensional surfaces while conserving threedimensional volume, line length in the transport plane, and orthogonal bed thickness (e.g. Griffiths et al., 2002). In this case, the choice of template horizon and location of a fixed pin control the unfolding process and govern the outcome of the restoration.

Pseudo three-dimensional restoration and forward modeling of fault-cored folds is appropriate in cylindrical folds where plane strain conditions limit displacement to within a single transport plane, but may not be valid in non-cylindrical folds. During the development of non-cylindrical folds a component of out-of-plane motion may develop where material displacement vectors deviate from the transport plane. While out-of-plane transport is very difficult to document in natural 


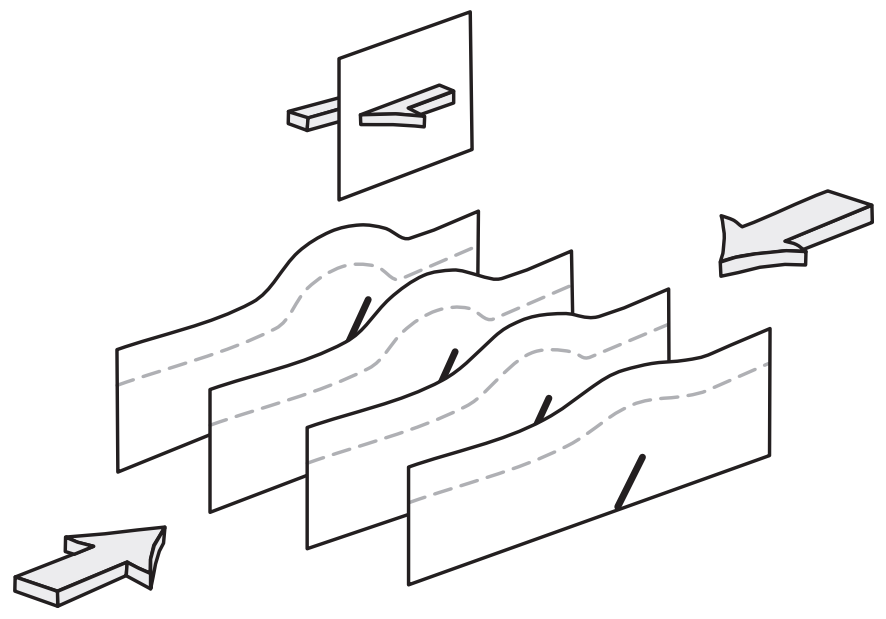

Fig. 1. Cartoon of a pseudo three-dimensional representation of a threedimensional structure. Restoration or forward models using 2D-3D methods would only resolve displacement and shear in the plane of section. Shear between the individual planes is neglected.

folds due to lack of traceable markers, out-of-plane transport has been documented in analog and numerical models (e.g. Fischer and Keating, 2005; Medwedeff and Krantz, 2002; Strayer and Suppe, 2002). Because many natural structures display complex, non-cylindrical geometries, an evaluation of the validity of pseudo three-dimensional modeling and restoration methods is needed. Of specific importance is an evaluation of where plane strain can be assumed and how much error will result from assuming plane strain where displacements deviate from the general transport plane.

In the same manner that the choice of pin plane and bed slip system govern the outcome of geometric restorations in two dimensions, we also expect bedding parallel slip to influence the fold shape and particle motion trajectories of threedimensional mechanical models. Laboratory experiments and natural folds show the strong dependency of fold shape and style on the spacing and density of interlayer slip surfaces (e.g. Chester et al., 1991; Erickson, 1996; Johnson and Johnson, 2000; Ramsay and Huber, 1987). Not coincidentally, flexural slip or layer parallel shear is a fundamental aspect of many two-dimensional geometric and kinematic models for fault related folding (Epard and Groshong, 1995; Erslev, 1991; Suppe, 1983; Suppe and Medwedeff, 1990). Despite the recognition that bed slip directly influences fold style, no studies evaluate the effect of three-dimensional bed parallel slip on fold shape, or evaluate the influence of bed slip on out-of-plane transport.

Within most structural restoration and forward models, the displacement field governs the orientations and magnitudes of local principal strain axes. Consequently, in order to model secondary strain features such as faults, fractures, cleavages, or parasitic folds in a fault-cored fold, the displacement field in the structure must reflect the natural processes that produced the fold. In providing guidelines for where plane strain may or may not be applied, we hope to reduce uncertainty in structural modeling and strain analysis.
In order to evaluate the validity of the plane strain assumption in non-cylindrical folds, we have constructed two three-dimensional boundary element method (BEM) models of simple non-cylindrical folds with and without slipping bed surfaces. Using a new technique of incrementally releasing infinitesimal strains and subsequently incrementing displacement on a subsurface fault we are able to model large strains and simulate folds with more realistic amplitudes that can be directly compared to natural folds (Fig. 2). Our goal is to evaluate the magnitude, structural position, and controls on the distribution of out-of-plane transport in threedimensional folds and provide guidelines of where pseudo three-dimensional models should and should not be applied. We show that out-of-plane transport is significant in the simplest non-cylindrical folds, and we suggest that complex non-cylindrical structures should not be modeled using plane strain exclusively. We also show that bedding slip surfaces exert a significant control on the magnitude and structural position of out-of-plane transport in our models.

\section{Methodology}

This study utilizes the boundary element method (BEM) code Poly3D (Thomas, 1994), which solves the governing equations of continuum mechanics for faults in a uniform, linear-elastic half space representing the Earth's upper crust. Three-dimensional BEM models (Crouch and Starfield, 1990) can solve for the complete three-dimensional deformation of fault-cored folds. Faults in the model are discretized into triangular elements on which either slip and opening or shear and normal tractions can be prescribed. Such tractions can be imposed by a remote stress or strain on the model.

Linear elastic models evaluate displacements most accurately for infinitesimal strains $(<1 \%)$ due to an assumption that the second-order displacement gradients are much smaller than the first-order displacement gradients and can be considered negligible for calculating strain (Crouch and Starfield, 1990; Jaeger and Cook, 1979). With < 1\% strain, linear elastic continuum mechanics produce folds of relatively small amplitude (e.g. Savage and Cooke, 2003). Comparison of BEM
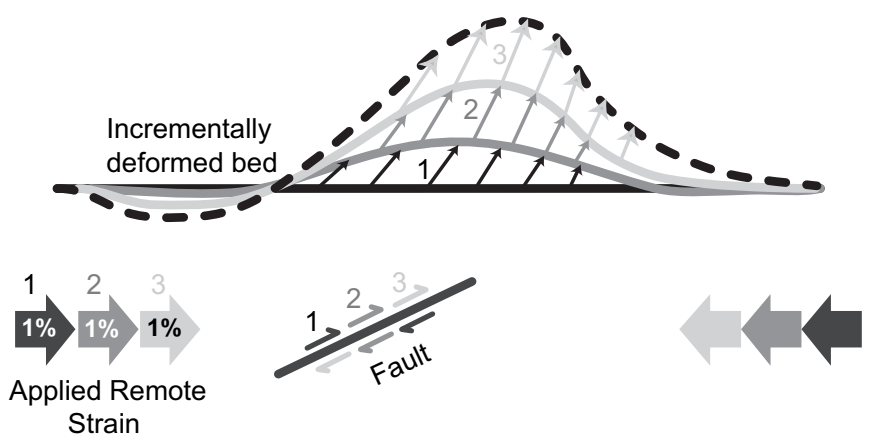

Fig. 2. Incrementing infinitesimal elastic strains to produce finite deformation observed in natural folds. Each increment of $1 \%$ strain induces slip on the fault and deformation of the suprajacent beds. These newly displaced beds form the input for the following increment in the model, such that infinitesimal strains are summed to produce finite deformation. Although not sketched here for simplicity, the fault surface also deforms with incremental strain. 
models to natural folds with relatively large amplitudes typically requires qualitative comparison between modeled small scale folds and natural folds, or prescribing slip to a subsurface fault in a displacement boundary value problem (e.g. Maerten, 1999; Maerten et al., 2001, 2000; Savage and Cooke, 2003).

In order to model folds with realistic amplitudes, we developed an innovative method of cumulatively adding infinitesimal strains of the faults and surrounding rock body (Fig. 2). At the initial step in the model, a remote strain is applied to faults in a linear elastic half space. Faults are allowed to slip freely, but not open or interpenetrate. Slip on the faults resulting from the applied remote strain produces both displacements in the surrounding linear elastic half space and rotations and translations of the fault surface itself (Fig. 2). Displacements after each increment of incremental strain are locked into the start of the next model, and points along horizontal surfaces representing bedding planes are traced during subsequent deformation.

The newly displaced faults and points along horizontal surfaces form the input for the next step of the incremental model. At the start of each increment, the model is unstressed so that stresses accumulated in the previous step are assumed to completely dissipate. A variety of processes act on 100010,000 year time-scales to alleviate accumulated stresses including micro-cracking, grain boundary sliding, calcite twinning, pressure solution, etc. (e.g. Sibson, 1986; Wright and Platt, 1982). Each of these inelastic deformational processes slowly reduces stresses in a manner that is simulated in our models as a complete stress drop. While we do not know to what degree and at what rate stresses are reduced, our observation of folds at the Earth's surface not presently under contraction informs us that such inelastic processes had to have acted in the past to 'lock in' the fold shape and prevent the layers from springing back to horizontal. Iterating the process with constant increments of remote strain produces folds of realistic amplitude and maintains accuracy of the mechanical model. The method also allows us to examine the finite deformation of interacting faults and slipping bedding planes during folding.

In order to simulate fault-related folding and examine the effect of bed parallel slip on out-of-plane transport, we compare two fault models. Both models have a $35^{\circ}$ dipping, elliptical fault that is elongate in the strike direction and centered at $4 \mathrm{~km}$ depth. Model 1 has only the elliptical fault in a uniform elastic half space (Fig. 3). Model 2 is constructed with two freely slipping bed surfaces (initially horizontal at 2 and $1 \mathrm{~km}$ depths) between the elliptical fault and the model's free surface (Fig. 3B). These models represent two scenarios within a continuum from no bed slip to significant slip along beds overlying the fault. To simulate sedimentary rocks near the Earth's surface, we have assigned shear modulus of 15,000 MPa and 0.25 for Poisson's ratio (Birch, 1966). Each model undergoes 50 increments of $1 \%$ strain, with the horizontal remote contraction parallel to the dip direction of the elliptical fault, and zero remote shear and zero remote strike parallel strain.
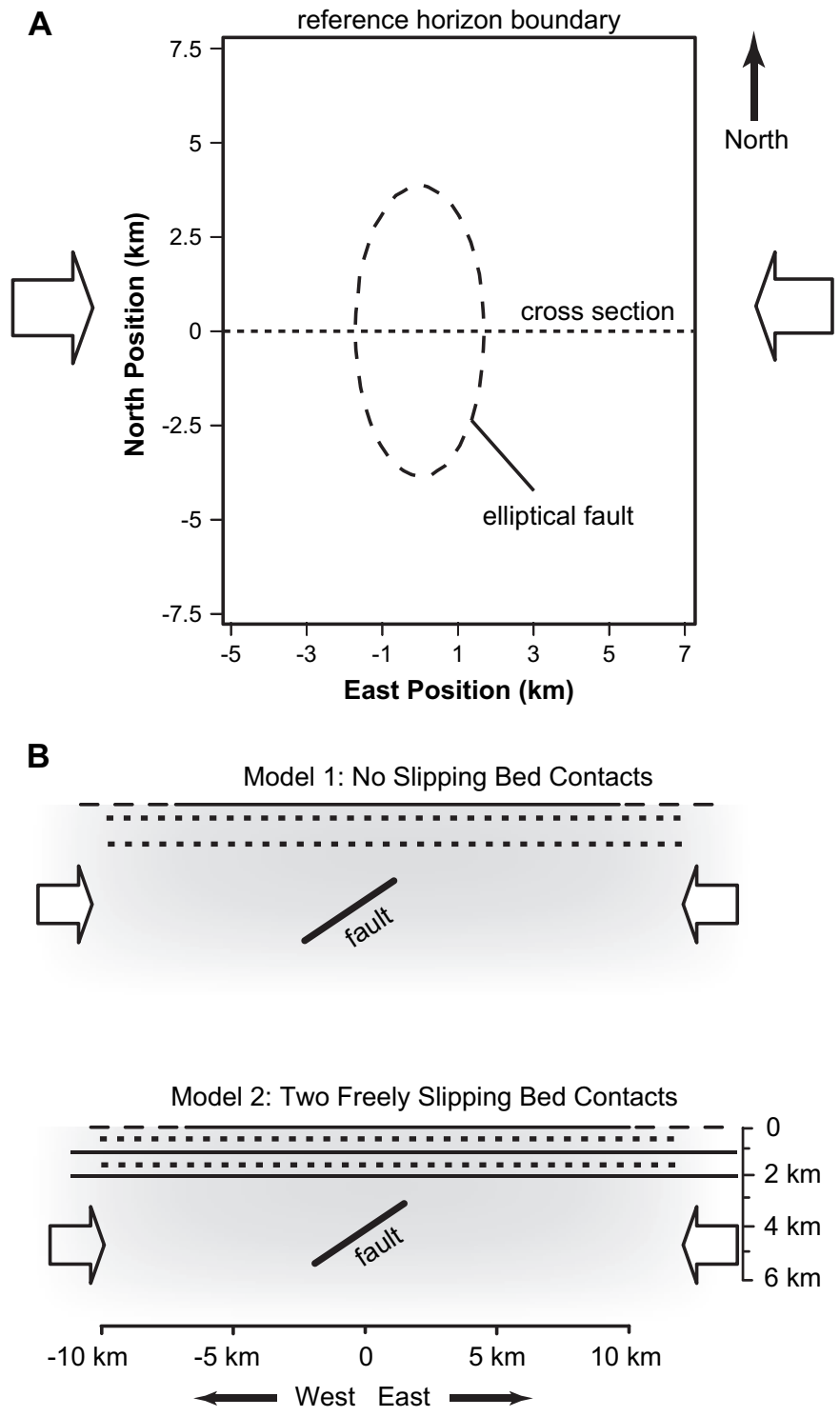

Fig. 3. Initial setup of the two models. (A) Map view of fault and horizontal extent of the reference horizon. Note that the reference horizon boundary is not the model boundary; the model extends infinitely in horizontal and depth directions. The elliptical fault (dashed ellipse) strikes north-south, has a westerly dip of $35^{\circ}$, is $8 \mathrm{~km}$ long in the north-south direction, $4 \mathrm{~km}$ long in the eastwest direction, and is centered at $4 \mathrm{~km}$ depth. The dotted line corresponds to the cross-sections in (B). (B) Cross-sectional views of the two initial model boundary conditions. Reference horizons (dotted lines) placed at 0.5 and $1.5 \mathrm{~km}$ depth are used to track folding deformation and to document differences in the displacement field that result from proximity to the fault and free surface of the model. In Model 2, bed slip surfaces (thin solid lines) extend laterally until the required condition of no slip at the lateral tips does not affect folding in the model.

\section{Model results}

We qualitatively compare fold shape and displacement trajectories at the two reference horizons in the models and in cross-sections (Figs. 4-6). To evaluate the influence of bed parallel slip on out-of-plane transport, we quantitatively compare the percentage of out-of-plane transport for each reference horizon, and normalize the out-of-plane displacement 
Model 1
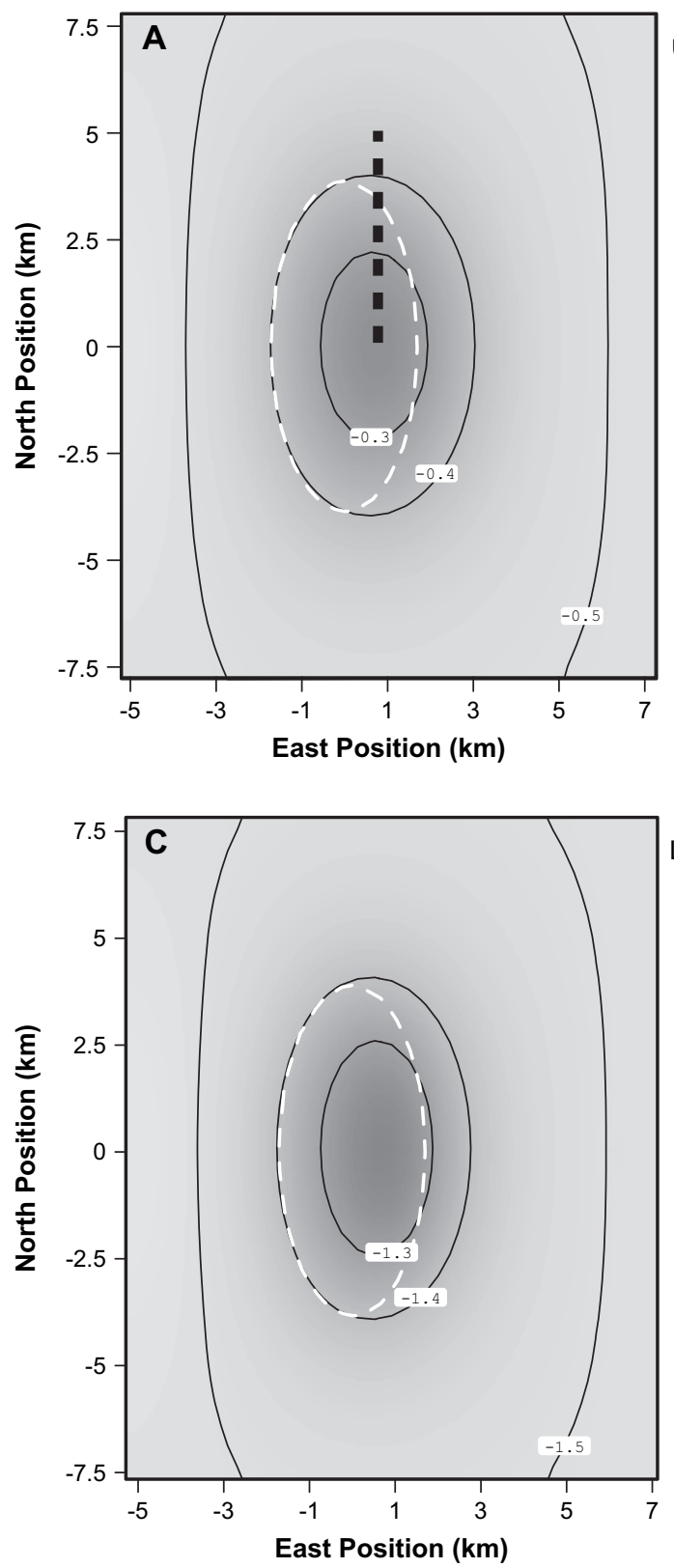

Model 2
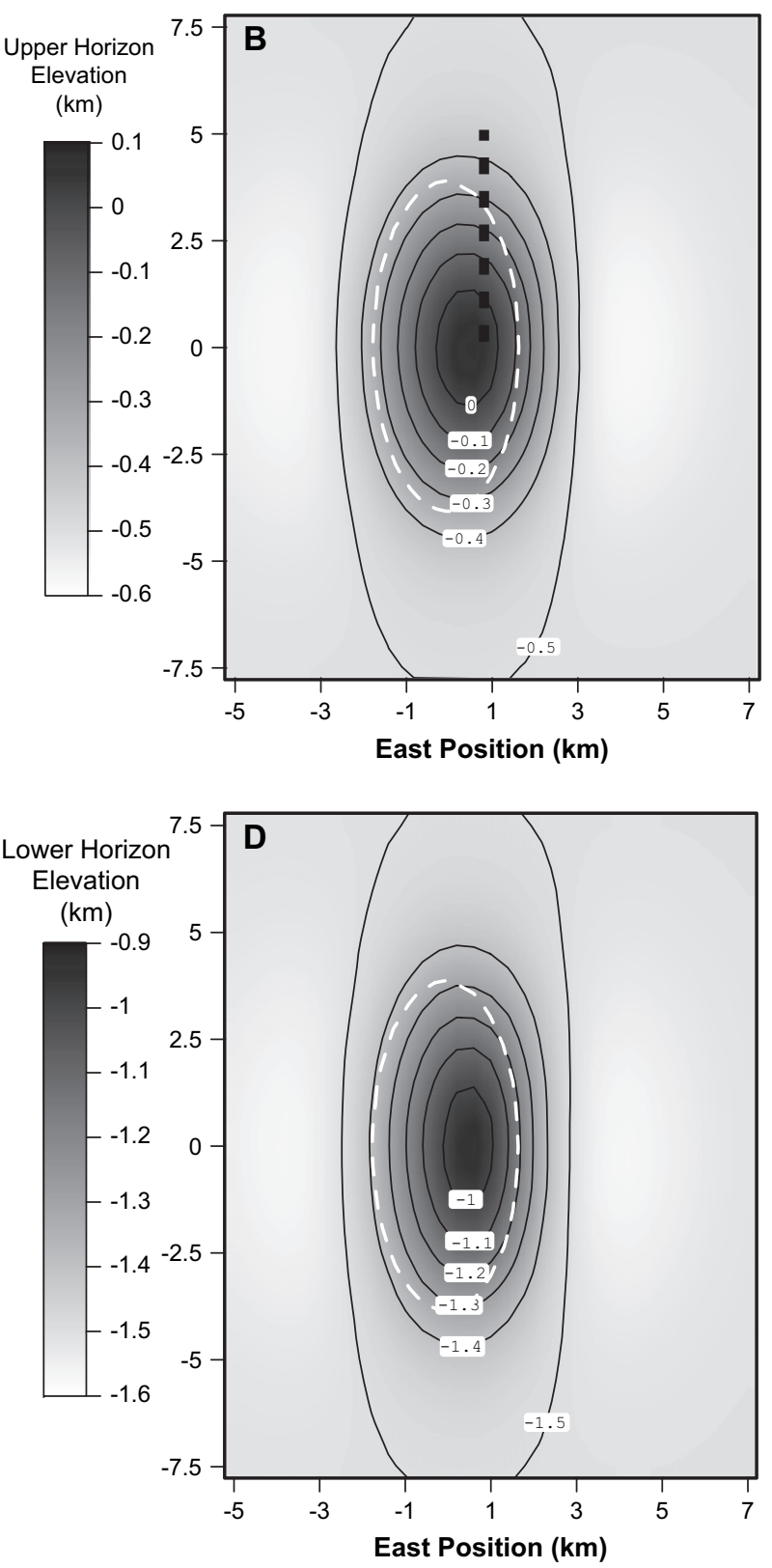

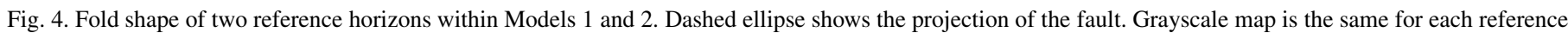

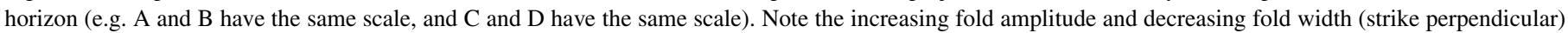

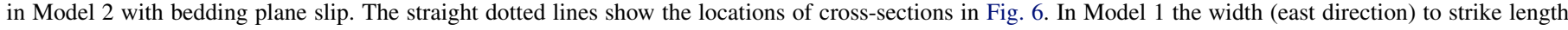
(north direction) of the fold is 0.125 , whereas the width to strike length of the fold is 0.03 in Model 2 .

to account for differences in displacement vector magnitude (Figs. 7-10).

\subsection{Final fold and fault shape}

After 50 increments of strain, both models produce a prominent doubly plunging anticline above the upper fault tip (Fig. 4). Model 1 has a broad anticline with low limb dips and small amplitude (Fig. 4A and C). The deeper horizon has a similar shape to the shallow horizon, but slightly greater amplitude, indicating amplitude increase with proximity to the fault tip. With the inclusion of bed slip surfaces in Model 2 (Fig. 4B and D), the amplitude of folding increases significantly; the difference in amplitude between the two models is more than $300 \mathrm{~m}$. The fold width to strike length ratios are also significantly different as flexural slip tightens the fold (Fig. 4) (e.g. Chapple and Spang, 1974; Johnson and Johnson, 2000; Ramsay and Huber, 1987).

The dipping fault and bed slip surfaces change shape and orientation due to deformation. Linear elastic fracture mechanics predicts that slip along a mode II crack is associated with a small degree of rotation (e.g. Lawn). Within the model, 

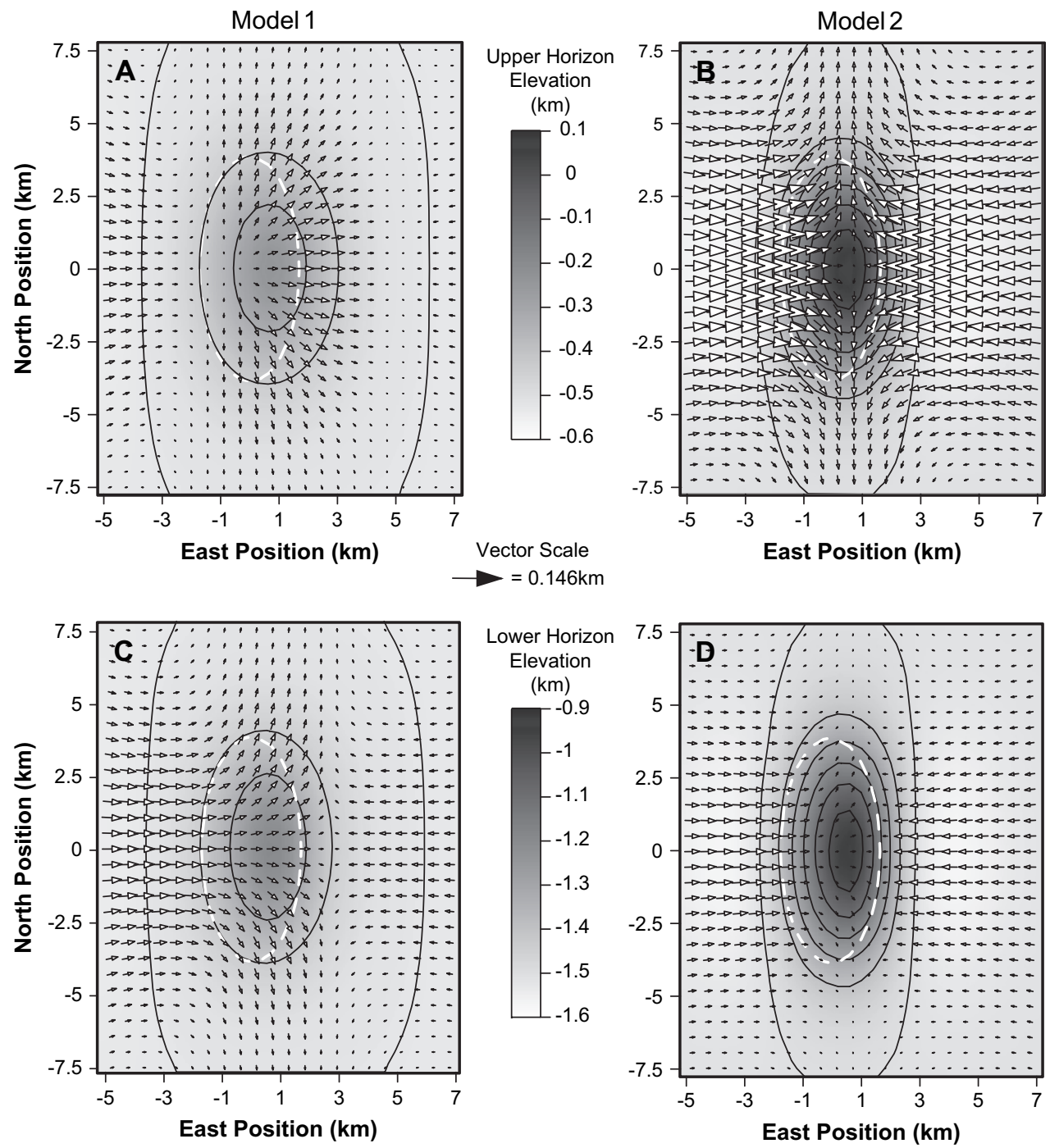

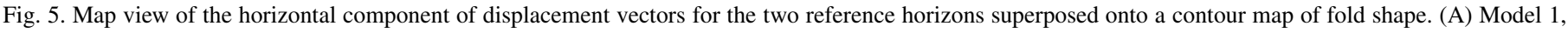

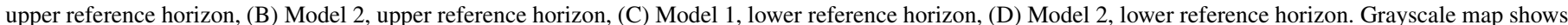

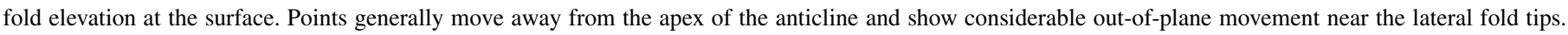

this rotation is about the strike of the fault and serves to steepen the fault. In Model 1 , the initially $35^{\circ}$ dipping fault steepens to an average dip of $40^{\circ}$. In Model 2, bed slip surfaces are folded into an anticline along with the nearby reference horizons (see supplementary material Model2.50.pdf). The dipping fault in Model 2 steepens to an average dip of $53^{\circ}$ and shows non-planar surface topology that is probably a result of interactions with the overlying bed slip surfaces. Flexural slip along dipping fold limbs produces an overall downward movement of material out of the anticline core, which lies directly above the upper fault tip. This outof-core displacement distorts the dipping fault.

\subsection{Displacement vectors}

In map view, displacement vectors are strikingly different between models with and without flexural slip. Model 1 without slipping bedding planes has displacement vectors forming a half-radial pattern in the hanging wall (Fig. 5A and C). The distribution of horizontal displacement differs with depth in Model 1; at shallow depths, horizontal displacements reach a maximum above the upper fault tip (Fig. 5A), whereas at greater depths, the largest horizontal displacements are in the hanging wall above the lower fault tip (Fig. 5C). Model 2 has a more symmetrical pattern of horizontal displacement than Model 1, with areas of large horizontal displacement to the east and west of the anticline, and relatively little horizontal displacement on the crest (Fig. 5B and D). Although vectors at the crest of the anticline in Model 2 appear relatively small in Fig. 5, they have a large vertical component (Fig. 6B) and are some of the largest displacements in the anticline. Horizontal displacement vector magnitudes are largest at the shallow reference depth in the model with flexural slip (Fig. 5B), but the general pattern of horizontal displacement does not change significantly between 0.5 and $1.5 \mathrm{~km}$ (Fig. 5B and D). 
A

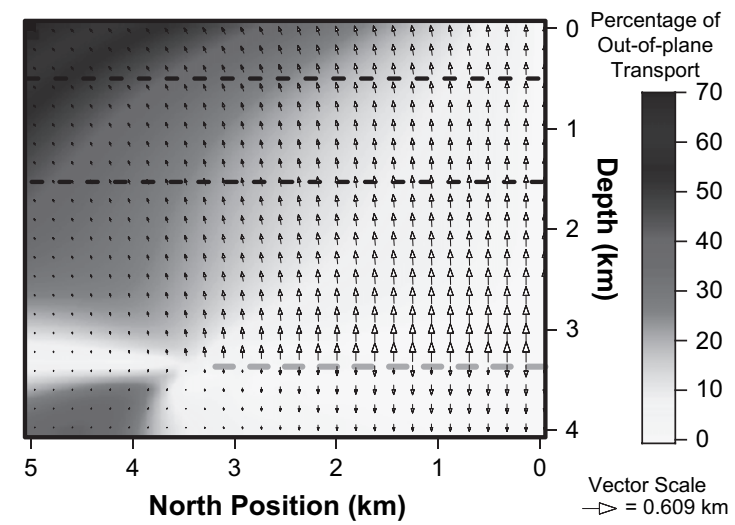

B

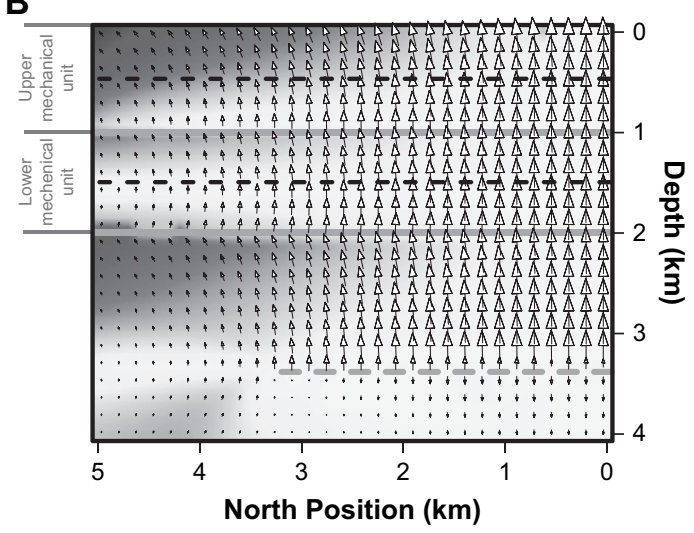

Fig. 6. North-south cross-sections perpendicular to the contraction direction and parallel to fault strike show displacement vectors superposed on density plots of percentage of out-of-plan transport. (A) Model 1 results with no flexural slip. (B) Model 2 results with two freely slipping bed slip surfaces. Location of the cross-sections is shown in Fig. 4. This figure shows the initial geometry of the fault (dashed gray lines), bed slip surfaces (solid gray lines), and reference horizons (dashed black lines); final positions of these surfaces can be inferred from the displacement pattern. The degree of out-of-plane transport decreases with depth and increases with proximity to the lateral fault tip. In Model 2, out-of-plane displacement is localized near bed slip surfaces and/or the free surface of the model. The lower reference horizon in Model 2 is located at a neutral surface, where out-of-plane displacement is at a minimum. Within Model 2, vectors change direction above and below bed slip surfaces.

The fold-strike parallel, or out-of-plane component of transport is evident from the obliquity of horizontal displacement vectors from the contraction direction. Displacement vectors are approximately parallel to the contraction direction at the apex of the anticline (north position $0 \mathrm{~km}$ ) and approximately perpendicular to the contraction direction near the lateral fault tips (north positions 4 and $-4 \mathrm{~km}$ ). In general, the component of out-of-plane transport is negligible near the apex of the anticline, and increases outward along strike. This trend is observed in both models, and at both reference horizon depths (Fig. 5).

The degree of out-of-plane transport varies with depth in both models. In general, the magnitude of out-of-plane displacement increases with vertical distance from the fault (Fig. 6A). The vertical displacement field in Model 1 is relatively continuous, with a smooth transition between sub-vertical displacements near the fault, and oblique displacements near the free surface of the model above the lateral fault tip (Fig. 6A). The

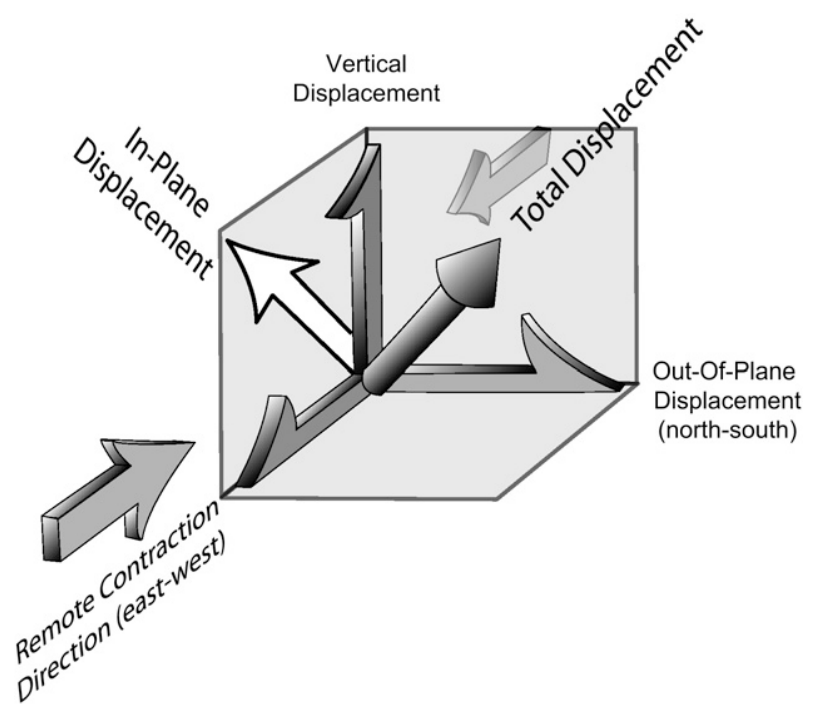

Fig. 7. Schematic diagram of vector components. The white arrow indicates the in-plane displacement vector that is the sum of the vertical and contraction parallel (east-west) vector components. The arrow pointing to the right indicates the out-of-plane displacement vector, which is the north-south component of displacement parallel to the fold axis.

same trend of decreasing out-of-plane transport with depth is also present in Model 2, although bed slip surfaces affect the spatial pattern of out-of-plane displacement (Fig. 6B). Below the lower bed slip surface, Model 2 resembles the displacement field of Model 1, with a smooth transition between sub-vertical vectors near the fault and oblique vectors near the lower bed slip surface (Fig. 6B). Above the lower bed slip surface are two discrete mechanical units bounded by upper and lower bed slip surfaces and the free surface of the model (Fig. 6). Within the lower unit, displacement vectors are vertical and parallel to the remote contraction direction near the center of the mechanical unit and oblique near the bed slip surfaces, forming a symmetrical pattern about the neutral surface of this unit. The upper mechanical unit has an asymmetric pattern with a relatively smooth transition from sub-vertical displacement vectors near the bed slip surface, to highly oblique vectors near the free surface of the model (Fig. 6).

Because out-of-plane displacement varies with depth in Model 2, the location of reference horizons biases the degree of out-of-plane displacement interpreted from the reported results. For example, the lower reference horizon lies at the center of the lower mechanical unit, which is a neutral surface where out-of-plane displacements are minimal (Fig. 6B). Therefore, the map view of the displacement field in Fig. 5D represents the minimum out-of-plane transport in that mechanical unit; reference horizons located near the bed slip surfaces would show significantly greater out-of-plane transport. Similarly, the upper reference horizon lies at the center of the upper mechanical unit, which displays intermediate degrees of outof-plane transport for that mechanical unit; more out-of-plane transport occurs above the reference horizon, whereas less out-of-plane transport occurs below the reference horizon (Fig. 6B). 
Model 1
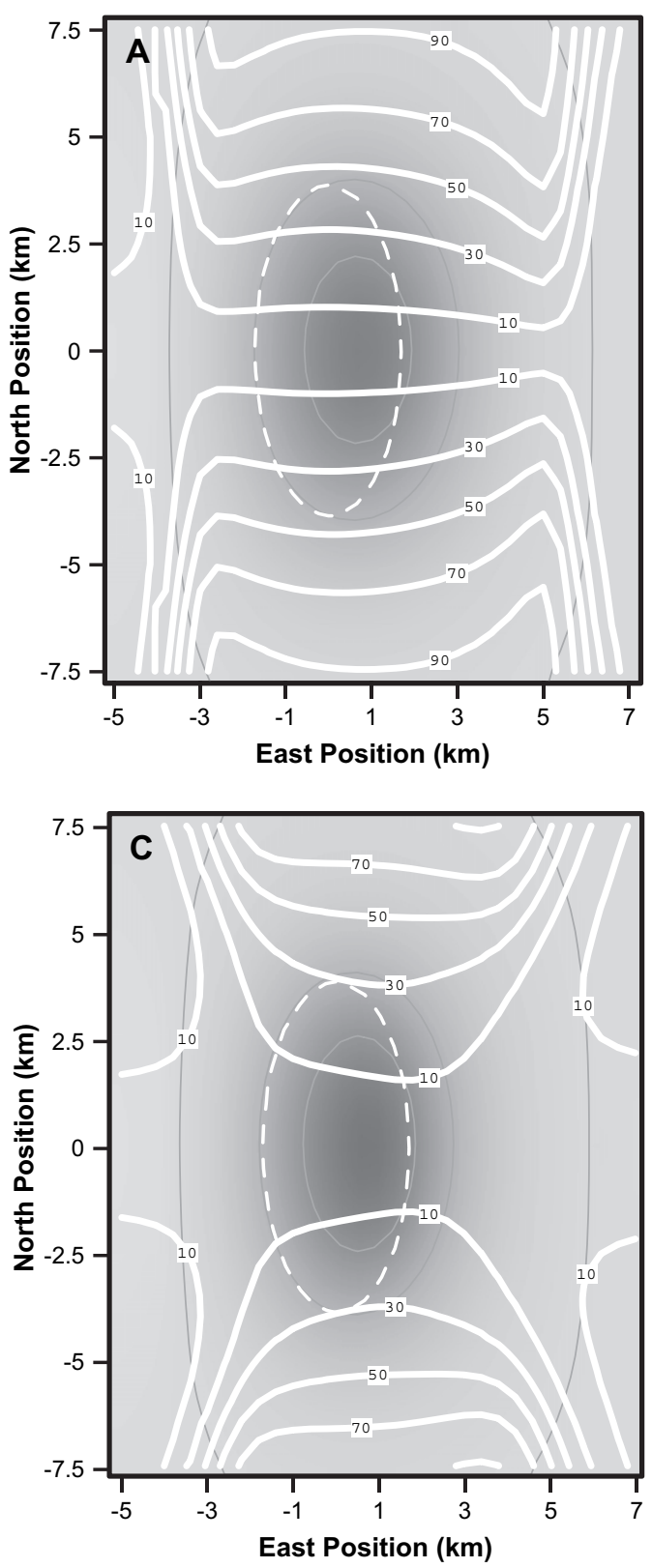

Model 2
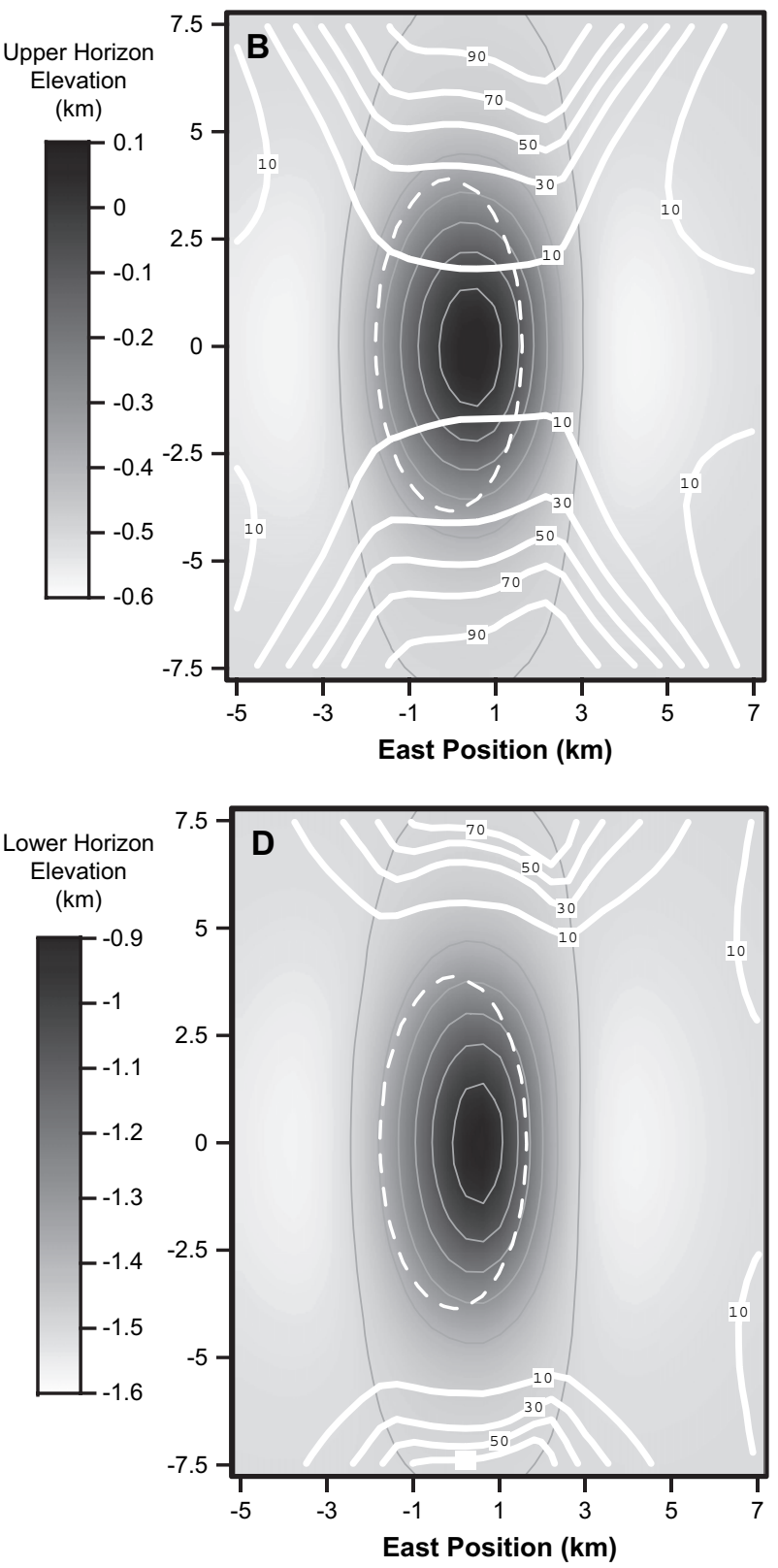

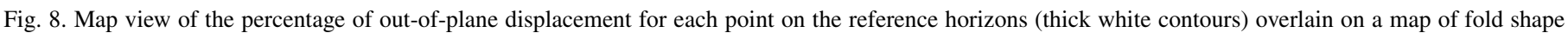

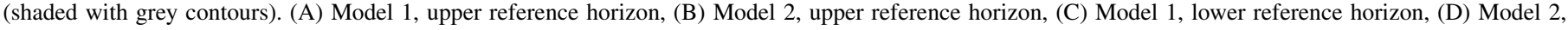

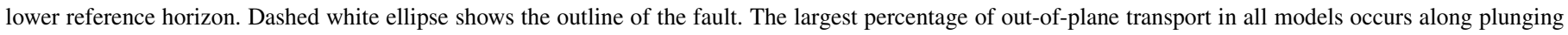
terminations of the anticline.

\subsection{Percentage of out-of-plane displacement}

The percentage of out-of-plane displacement can be calculated by dividing the out-of-plane component of motion by the total displacement (Fig. 7). This provides a quantitative measure of the percentage of out-of-plane displacement in order to highlight structural positions where out-of-plane transport may be more or less prevalent in plunging anticlines. This calculation represents the percent error that might be incurred when incorrectly assuming plane strain in a pseudo threedimensional forward model or restoration of a non-cylindrical fold.
In the absence of flexural slip, a significant percentage of out-of-plane displacement occurs near the plunging termination of the anticline. Along the upper reference horizon of Model 1, up to $90 \%$ of the displacement is out-of-plane in this location (Fig. 8A). Along the lower reference horizon in Model 1, up to $70 \%$ of the displacement is out-of-plane near the plunging termination of the anticline (Fig. 8C). In general, the greatest percentage of out-of-plane displacement tends to occur near the lateral fold terminations and near the free surface of the model (Fig. 6A).

Model 2 has a significantly different distribution of outof-plane transport than Model 1 (Fig. 8B and D). The maximum 

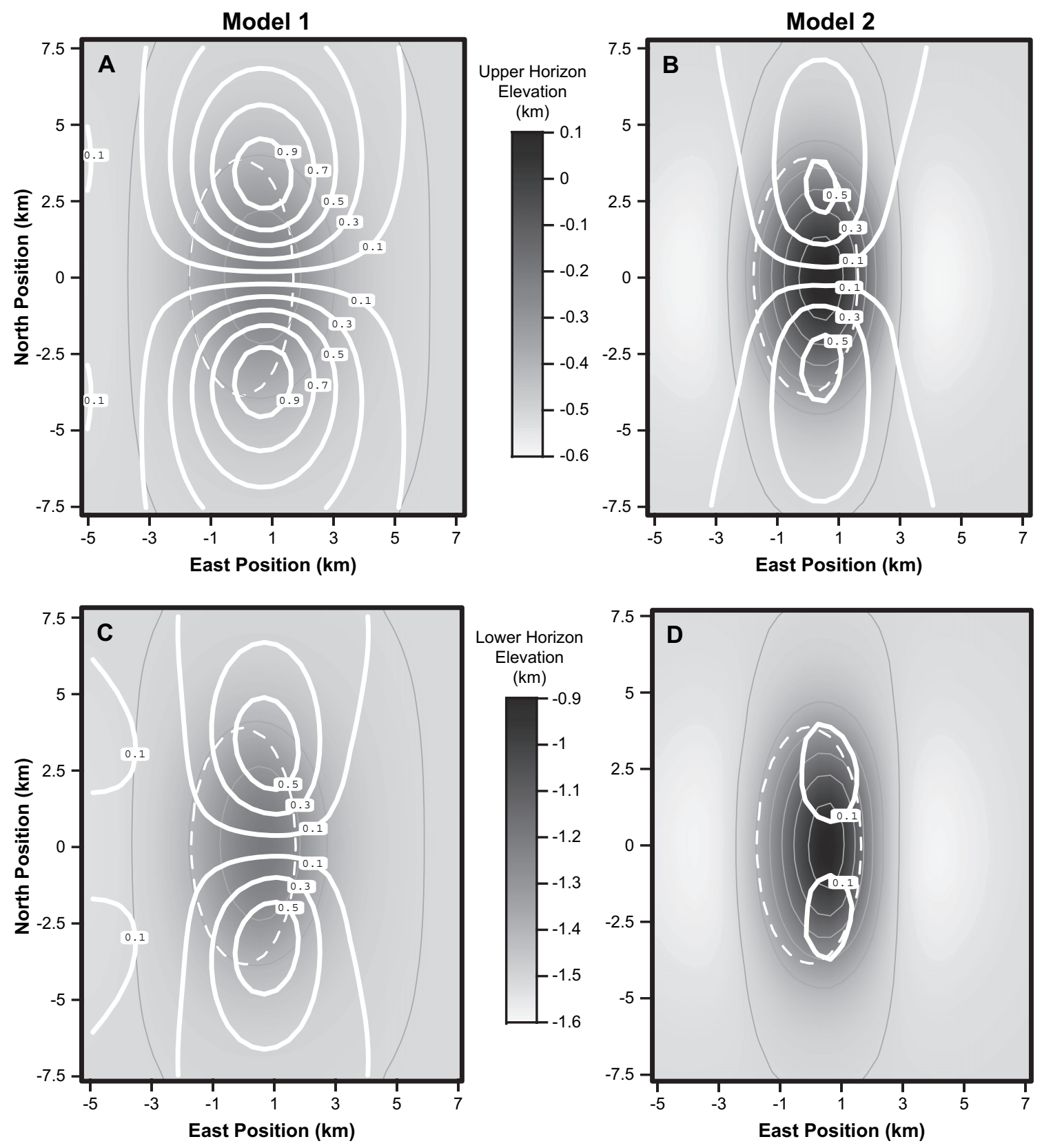

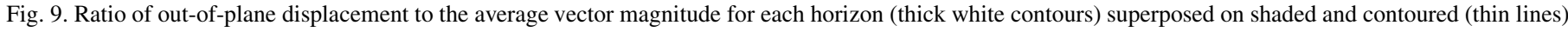

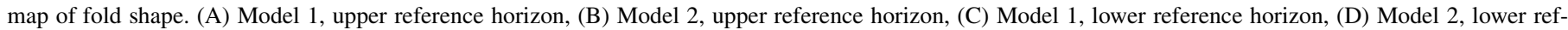

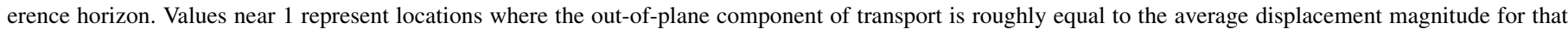
horizon. Greatest normalized out-of-plane displacement occurs near the fold axis between the apex and the plunging terminations of the fold.

percentages of out-of-plane transport at the most distal tips of the folds are the same for both models, but larger portions of the anticline in Model 2 have lesser percentage of out-of-plane transport than Model 1. The flexural slip within Model 2 complicates the pattern of out-of-plane transport. Because the lower reference horizon of Model 2 samples the neutral surface of the lower mechanical unit, this horizon shows negligible out-of-plane transport along much of the fold (Fig. 6B). In cross-section, out-of-plane displacements within the lower mechanical unit are as much as $40 \%$ near the bed slip surfaces and $0 \%$ along the neutral surface at the same structural position (Fig. 6B). Thus, the neutral surface sampled in Fig. 8D provides a minimum estimate of out-of-plane transport.

\subsection{Normalized ratio of out-of-plane transport}

While useful for comparing the amount of out-of-plane displacement at specific points along the fold, the percentage of out-of-plane transport does not take into account variations in the displacement magnitudes at different structural positions. For example, Fig. 8 shows that percentages of 

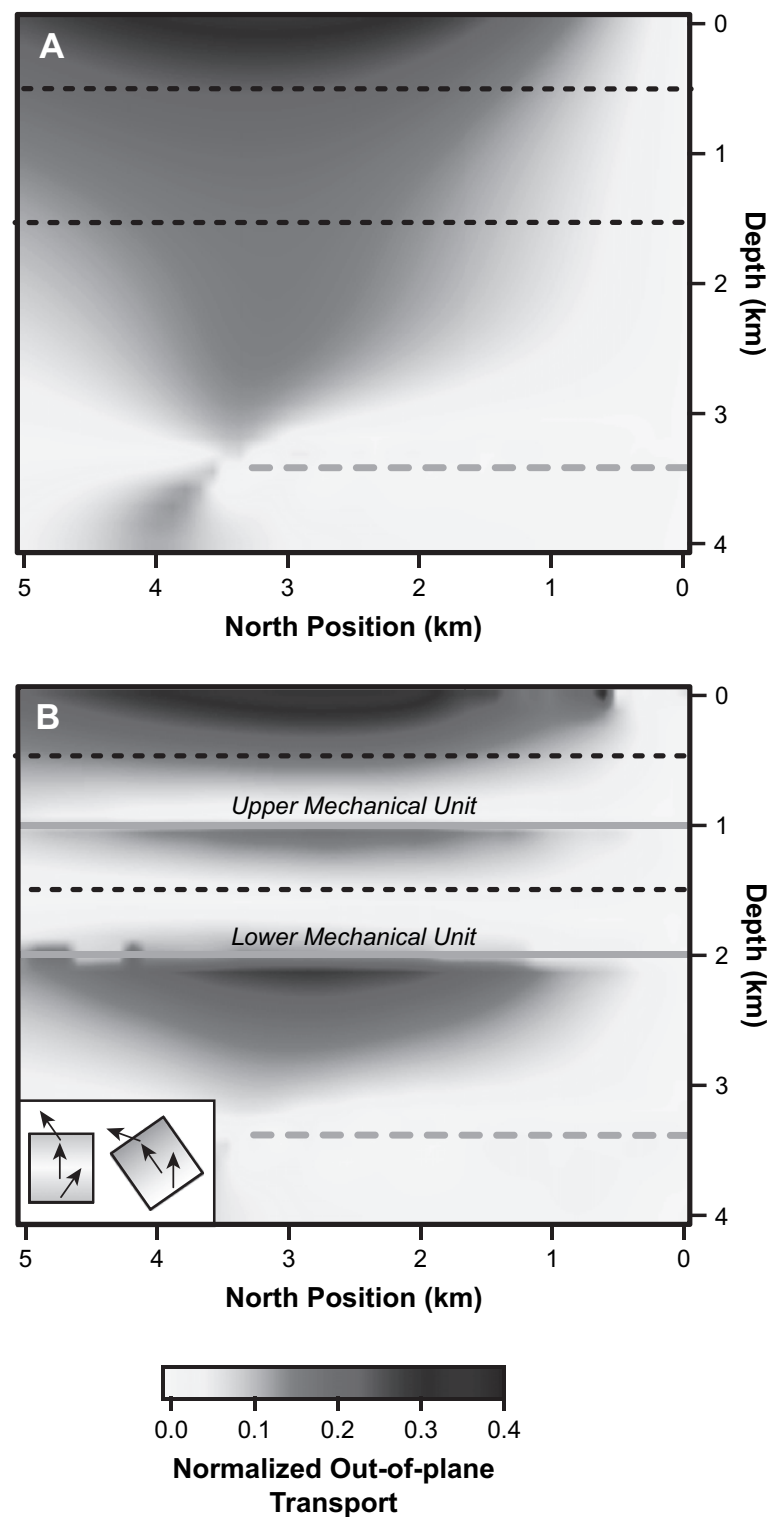

Fig. 10. North-south cross-section showing the ratio of out-of-plane displacement to the average displacement magnitude within the vertical section. (A) Model 1 with no flexural slip. (B) Model 2 with two freely slipping bed slip surfaces. Section location is shown in Fig. 4. This figure shows the initial geometry of the fault (dashed gray lines), bed slip surfaces (solid gray lines), and reference horizons (dotted black lines). Significant out-of-plane displacements arise above the lateral fault tip in both models. Generally out-of-plane displacement increases with distance above the fault. Flexural slip in Model 2 adds complexity to this pattern by reduced out-of-plane displacement near the base of each mechanical unit and augmenting out-of-plane slip near the top of the unit.

out-of-plane transport are largest near the lateral fold tips, however, displacement magnitudes in this structural position are insignificant compared to displacements near the center of the anticline. To highlight areas where the magnitudes of out-of-plane displacement are significant, we normalize the out-of-plane component of displacement by the average displacement magnitude for all points in each reference horizon. For example, the average displacement magnitude for the upper reference horizon in Model 1 is $77.4 \mathrm{~m}$, so the out-of-plane component of each displacement vector in the upper reference horizon in Model 1 is divided by 77.4. This calculation downplays the insignificantly small displacement vectors, and highlights areas where out-of-plane displacement is close, equal to, or greater than the average displacement for a given reference horizon (values near 1 on Fig. 9).

When normalized by the average displacement, the most significant magnitudes of out-of-plane transport are located near the anticlinal axis between the apex (north position 0 ) and the lateral fold tips for both models (north positions $-4 \mathrm{~km}$ and $4 \mathrm{~km}$, Figs. 9 and 10). The position of highest normalized out-of-plane transport is the same along all reference horizons and occurs above the lateral fault tips. The reference horizon at $500 \mathrm{~m}$ depth in Model 1 has the largest ratios, with out-of-plane transport nearly equaling the average displacement along parts of the fold axis (Fig. 9A). The deeper reference horizon in Model 1 has less out-of-plane displacement, with ratios up to 0.6 (Fig. 9C).

Flexural slip within Model 2 significantly reduces outof-plane transport at the reference horizons. The upper reference horizon in Model 1 has relatively large out-of-plane displacement, with normalized out-of-plane displacement up to 0.5 along the fold axis. In contrast, out-of-plane displacement appears to be relatively insignificant in the deeper bed in Model 2 , with ratios of 0.1 . However, this reference horizon may not be sampling a representative out-of-plan displacement for the lower mechanical unit.

In cross-section, both models show increasing out-of-plane displacement with distance above the fault tip (Fig. 10A and B), although this pattern is complicated by the effects of flexural slip in Model 2 (Fig. 10B). Near the fault, displacements parallel the slip direction of the fault, whereas away from the fault, the displacements reflect the uplift and arching of the folded material. Flexural slip within Model 2 augments outof-plane displacement at the tops of mechanical units and reduces these displacements at the bases. This asymmetry arises from fold-associated tilting of both the mechanical unit and the displacement field within that unit (Fig. 10B). In the inset absence of any tilt of flexural-slipping layers, the lower half of the mechanical unit moves upwards and toward the apex of the anticline, the center moves directly up, and the upper half moves upwards and away from the apex (Fig. 6B). The tilting of this displacement pattern away from the apex of the fold during folding rotates the displacements in the top and center of the mechanical unit away from vertical and rotates the displacements in the lower half closer to vertical (inset Fig. 10B). Consequently, out-of-plane displacements are greater at the top than at the base of individual mechanical units.

\section{Effect of friction coefficient and spacing of bed slip surfaces on fold shape}

The models presented thus far represent two scenarios: a condition of no flexural slip or all bonded layer contacts (Model 1) and a condition of frictionless slip on two bed slip surfaces (Model 2). The conditions of bonded and freely 
slipping beds represent end-members of the expected conditions along natural layer contacts. Natural bedding surfaces will have some cohesion and frictional resistance to slip due to asperities that would yield flexural behavior between that of bonded layers or freely slipping layer contacts. Furthermore, natural stratigraphic sequences typically have more than two contacts to accommodate flexural slip. To assess the effects of friction coefficient and spacing of sliding bed surfaces, we investigate two-dimensional models through the center of the three-dimensional fold, where we have showed out-of-plane transport to be negligible (Figs. 8 and 9).

The two-dimensional formulation allows us to use an existing BEM code, FRIC2D, that incorporates frictional slip and reduces computational demands so that we may explore the effects of more than two sliding contacts. Along frictional faults within FRIC2D, the material properties of the faults are prescribed (e.g. cohesion and friction coefficient) rather than the displacements and/or tractions as with other BEM elements (Cooke, 1997; Crouch, 1979; Crouch and Starfield, 1990). FRIC2D has been used to examine the influence of bedding-plane slip within folds (Cooke et al., 2000; Cooke and Pollard, 1997), the influence of bedding-plane slip on fracture propagation (Cooke and Underwood, 2001), compaction of sediment over buried craters (Buczkowski and Cooke, 2004), and the interaction of faults within the Los Angeles metropolitan region (Cooke and Kameda, 2002).

The two-dimensional models investigate four cases of layer contacts overlying a fault: (1) bonded layer contacts, (2) two evenly spaced frictionally slipping layer contacts, (3) two evenly spaced freely slipping layer contacts, and (4) frictional slip along five contacts (Fig. 11: inset). The initial geometry of faults and bedding surfaces within the two-dimensional model is chosen as step 25 (of 50) from the three-dimensional incremental model. This ensures that the results are applicable to most stages of folding when beds are not horizontal. The right hand side of the model is translated to the left $275 \mathrm{~m}$ to provide about $1 \%$ contraction. Lithostatic gravitational stresses are superposed onto the model to give realistic resistance to slip; we use sediment density of $2700 \mathrm{~kg} / \mathrm{m}^{3}$. Because frictional slip is inelastic and subsequently path-dependent, we apply the contraction monotonically within four steps. The

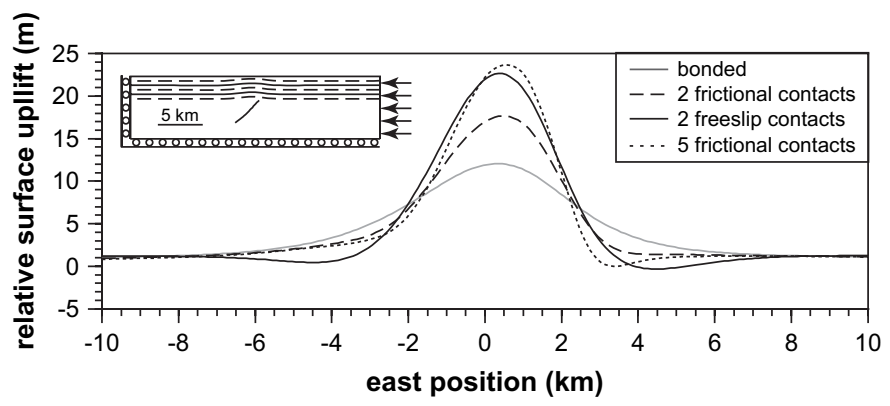

Fig. 11. Surface uplifts for four different frictional bed slip boundary conditions in FRIC2D. Inset figure shows the model boundary conditions, which are derived from the 25th increment in the three-dimensional Model 2. A model with two freely slipping contacts may approximate the condition of five or more frictional contacts. dipping fault is free to slip while bed contacts have a moderate friction coefficient of 0.65 and $3.25 \mathrm{Ma}$ cohesion (e.g. Cooke and Underwood, 2001).

Comparison of uplift patterns in the two-dimensional frictional and free slip models provides a qualitative calibration of the three-dimensional free slip model results to more realistic frictional behavior of layered sequences. The bonded and two freely slipping layer contact conditions correspond to conditions in the three-dimensional Models 1 and 2 respectively. The uplift patterns of these two conditions plot as distinct extremes, with the bonded layers producing a broad uplift pattern, and the two freely slipping layer contacts producing a localized uplift. The 2D model with two frictional slip contacts produces fold shape intermediate to the bonded and two freely slipping contact models, suggesting that frictional resistance between contacts significantly affects fold shape, and therefore displacement vectors in the model. With the addition of additional frictional contacts, the fold tightens and more closely resembles the model with two freely slipping contacts. This suggests that Model 2 with limited freely slipping contacts can approximate a case of many frictional contacts.

\section{Discussion}

The results of this study suggest that out-of-plane transport can be significant in plunging fault-cored folds. These models, while simple in fault configuration, demonstrate many important processes and provide general guidelines on the distribution of out-of-plane transport in plunging fault-cored anticlines. However, we caution against direct comparison with natural structures because the distribution of out-of-plane transport will vary significantly depending on the fault configuration, boundary conditions, and perhaps most importantly, the slip distribution on the fault. In general, when the slip distribution changes rapidly over a small fault area, we expect larger magnitudes of out-of-plane transport and less cylindrical folds. Changes in slip distribution also explain why the most significant out-of-plane transport in our models occurs above the lateral fault tips because the slip distribution rapidly approaches zero at those structural positions.

Comparing Models 1 and 2 illustrates the influence of bed slip surfaces on out-of-plane transport. Large components of out-of-plane transport arise in models with no bed slip above the fault, suggesting that out-of-plane transport is most significant in relatively massive rocks that resist flexural slip. Thick sequences of massive carbonates, intrusive igneous rocks, and basement uplifts may provide such conditions. However, because fault-cored folds often form in layered stratigraphy where bed slip is an important aspect of the folding process, Model 2 may be a more representative model of folding conditions.

The three-dimensional models presented here highlight structural domains where out-of-plane displacement is significant and where plane strain can be assumed. For example, out-of-plane displacement is localized above the lateral fault tips and plane strain assumptions should be avoided at this structural position (Figs. 9 and 10). Although flexural slip 
reduces the overall errors incurred by assuming plane strain near the fault tips (Fig. 10), local errors may be quite significant. Within cross-section, bed slip surfaces serve to compartmentalize out-of-plane displacement within distinct mechanical units. Although our model has only two mechanical units we can generalize from these results that out-of-plane displacement within folded sedimentary strata is enhanced at the tops of mechanical units (Figs. 6B and 10B). Consequently, when utilizing plane strain fold restorations and models, consideration should be given to the errors that arise in these regions.

Three-dimensional restorations are commonly designed to predict the location and orientation of secondary structures such as faults and joints that may serve as subsurface flow conduits for hydrocarbons, groundwater contaminants, and other subsurface fluids (e.g. Hennings et al., 2000). Fracture orientations in these cases are usually inferred from maximum or minimum curvature direction, or from inference of strain axes from shear between transport planes (e.g. Fischer and Wilkerson, 2000; Hennings et al., 2000). A fracture prediction using fully three-dimensional models may locally differ significantly from a pseudo three-dimensional one because the outof-plane component of displacement near flexural slip surfaces and the free surface of the model may strongly affect the orientation of strain axes that are used to predict fault and fracture orientations. In other words, if one were to predict strain axes using the displacement field from a pseudo threedimensional model, those strain axes might be incorrect because the displacement field used to calculate those strain axes would not take into account the out-of-plane displacement in the model.

The new incremental models of this study show some new results that may have implications for the development of fault systems. During progressive folding, the underlying thrust fault is expected to both steepen and distort, due to slip along the fault and overlying bedding planes (see Supplementary Model2.pdf). During later stages in folding we might expect that the thrust fault that initially was ideally configured to accommodate horizontal contraction later to have inefficiently steep dips and rough topology. At some point inefficient thrust faults may become inactive in favor of the development of new more shallowly dipping and more planar faults. Although the ceasing of fault slip due to progressively unfavorable dips has been described (e.g. Jackson and McKenzie, 1983; Sibson, 2001), to our knowledge the influence of progressive surface roughness has not yet been examined.

The results presented in this paper focus on the overall displacement trajectories during the entire evolution of a faultcored fold, thus ignoring the temporal development of displacement trajectories and stresses in the incremental model. The initial displacement and stress field is dramatically different than stresses in the later stages of folding due to fold tightening and amplification by flexural slip. For example, slip along bed surfaces in the initial stages of folding are only due to slip on the underlying fault because bed slip surfaces are oriented parallel to the contraction direction (e.g. Cooke and Pollard, 1997; Nino et al., 1998). As folding progresses, bed slip surfaces rotate toward angles more favorable to slip, thus contributing to fold amplification (e.g. Chapple and Spang, 1974; Johnson and Johnson, 2000; Ramsay and Huber, 1987). The changing stress state during fold evolution has important implications for structural restoration and joint and fracture prediction.

\section{Conclusions}

Displacement trajectories in three-dimensional BEM models show that out-of-plane transport accounts for a significant component of the total displacement in fault related folds. These results have significant implications for restoration and modeling of plunging folds. The distribution of out-of-plane transport depends on the fault configuration and the slip distribution on the fault such that where large variations in slip distribution occur, large amounts of out-of-plane transport occur. The most significant out-of-plane transport occurs where there are no slipping bed surfaces and above the lateral fault terminations. Therefore, plane strain should not be assumed in massive strata that resists slip and across the lateral terminations of folds. Furthermore, out-of-plane transport increases with distance above the fault, so the most significant errors may arise near the Earth's surface in plane strain models.

Fault-cored folds are commonly found in layered sedimentary strata where flexural slip is common (Epard and Groshong, 1995; Erslev, 1991; Suppe, 1983; Suppe and Medwedeff, 1990). Where bedding plane slip occurs in non-cylindrical folds, outof-plane displacement is heterogeneously distributed because individual slip surfaces compartmentalize out-of-plane transport within each mechanical stratigraphic unit. Mechanical units bounded by bed slip surfaces generally have little out-of-plane transport in the middle of the mechanical unit, but large outof-plane displacements near the upper portions of the mechanical unit.

Our results have implications for current and future forward models and restorations of fault related folds. We have highlighted structural domains on non-cylindrical folds where the plane strain assumption of zero out-of-plane displacement will produce errors. Our results also suggest that inferring stress or strain from the plane strain models may be problematic for plunging fault-cored anticlines, as plane strain models may not account for the heterogeneity of out-of-plane stresses that would likely occur on the scale of each mechanical unit.

\section{Acknowledgments}

Acknowledgement is made to the donors of the American Chemical Society Petroleum Research Fund in support of this research. Comments and suggestions by Eric Erslev and Dolores Robinson improved the paper. Poly3D modeling software was provided by IGEOSS, and model building and visualization was facilitated by 3DMove software by Midland Valley, Ltd. We heartily thank Gavin Andresen for programming assistance and Don Wise for advice on sketches. 


\section{Appendix A. Supplementary material}

Supplementary material for this manuscript can be downloaded at doi:10.1016/j.jsg.2007.03.011.

\section{References}

Bernal, A., Hardy, S., 2002. Syn-tectonic sedimentation associated with threedimensional fault-bend fold structures: a numerical approach. Journal of Structural Geology 24, 609-635.

Birch, F., 1966. Compressibility: elastic constants, Sec 7. Geological Society of America Memoir 97, 97-173.

Buczkowski, D.L., Cooke, M.L., 2004. Compaction and shrinkage over buried impact craters: implications for thickness and nature of cover material in Utopia Planitia, Mars. Journal of Geophysical Research Planetary 109, doi:10.1029/2003JE002144.

Chapple, W.M., Spang, J.H., 1974. Significance of layer-parallel slip during folding of layered sedimentary rocks. Geological Society of America Bulletin $85,1523-1534$.

Chester, J.S., Logan, J.M., Spang, J.H., 1991. Influence of layering and boundary conditions on fault-bend and fault-propagation folding. Geological Society of America Bulletin 103, 1059-1072.

Cooke, M.L., 1997. Predicting fracture localization in folded strata from mechanical stratigraphy and fold shape: case study of East Kaibab Monocline, Utah. International Journal of Rock Mechanics and Mining Sciences. Geomechanics Abstracts 34, 3-4.

Cooke, M.L., Kameda, A., 2002. Mechanical fault interaction within the Los Angeles Basin: a two-dimensional analysis using mechanical efficiency. Journal of Geophysical Research 107 (B7), 2146.

Cooke, M.L., Mollema, P., Pollard, D.D., Aydin, A., 2000. Interlayer slip and joint localization in East Kaibab Monocline, Utah: field evidence and results from numerical modeling, in: Cosgrove, J.W., Ameen, M.S. (Eds.), Geological Society of London Special Publication on Forced Fold and Associated Fractures 169, London, pp. 23-49.

Cooke, M.L., Pollard, D.D., 1997. Bedding-plane slip in initial stages of faultrelated folding. Journal of Structural Geology 19, 3-4.

Cooke, M.L., Underwood, C.A., 2001. Fracture termination and step-over at bedding interfaces due to frictional slip and interface debonding. Journal of Structural Geology 23, 223-238.

Cristallini, E.O., Allmendinger, R.W., 2001. Pseudo 3-D modeling of trishear fault-propagation folding. Journal of Structural Geology 23, 1883-1899.

Crouch, S.L., 1979. Computer simulation of mining and faulted ground. Journal of the South African Institute of Mining and Metallurgy 79, 159-173.

Crouch, S.L., Starfield, A.M., 1990. Boundary Element Methods in Solid Mechanics. Unwin Hyman, London.

Epard, J.L., Groshong, R.H., 1995. Kinematic model of detachment folding including limb rotation, fixed hinges and layer-parallel strain. Tectonophysics $247,85-103$.

Erickson, S.G., 1996. Influence of mechanical stratigraphy on folding vs. faulting. Journal of Structural Geology 18, 443-450.

Erslev, E.A., 1991. Trishear fault-propagation folding. Geology 19, 617-620.

Fischer, M.P., Keating, D.P., 2005. Photogrammetric techniques for analyzing displacement, strain, and structural geometry in physical models: application to the growth of monoclinal basement uplifts. Geological Society of America Bulletin 117, 3-4.
Fischer, M.P., Wilkerson, M.S., 2000. Predicting the orientation of joints from fold shape: results of pseudo-three-dimensional modeling and curvature analysis. Geology Boulder 28, 15-18.

Griffiths, P., Jones, S., Salter, N., Schaefer, F., Osfield, R., Reiser, H., 2002. A new technique for 3-D flexural-slip restoration. Journal of Structural Geology 24, 773-782.

Hennings, P.H., Olson, J.E., Thompson, L.B., 2000. Combining outcrop data and three-dimensional structural models to characterize fractured reservoirs: an example from Wyoming. AAPG Bulletin 84, 830-849.

Jackson, J., McKenzie, D., 1983. The geometrical evolution of normal faults. Journal of Structural Geology 5, 471-482.

Jaeger, J.C., Cook, N.G.W., 1979. Fundamentals of Rock Mechanics, third ed. Chapman and Hall, London.

Johnson, K.M., Johnson, A.M., 2000. Localization of layer-parallel faults in San Rafael Swell, Utah and other monoclinal folds. Journal of Structural Geology 22, 1455-1468.

Maerten, L., 1999. Mechanical interaction of intersecting normal faults: theory, field examples, and applications. Unpublished $\mathrm{PhD}$ thesis, Stanford University, CA.

Maerten, L., Gillespie, P., Pollard, D.D., 2001. Effect of local stress perturbation on secondary fault development. Journal of Structural Geology 24, 145-153.

Maerten, L., Pollard, D.D., Karpuz, R., 2000. How to constrain 3-D fault continuity and linkage using reflection seismic data: a geomechanical approach. AAPG Bulletin 84, 1311-1324.

Medwedeff, D.A., Krantz, R.W., 2002. Kinematic and analog modeling of 3-D extensional ramps: observations and a new 3-D deformation model. Journal of Structural Geology 24, 763-772.

Nino, F., Philip, H., Chery, J., 1998. The role of bed-parallel slip in the formation of blind thrust faults. Journal of Structural Geology 20, 503-516.

Ramsay, J.G., Huber, M.I., 1987. The Techniques of Modern Structural Geology. In: Folds and Fractures, Volume 2. Academic Press, London, U.K.

Salvini, F., Storti, F., 2002. Three-dimensional architecture of growth strata associated to fault-bend, fault-propagation, and decollement anticlines in non-erosional environments. Sedimentary Geology 146, 1-2.

Savage, H.M., Cooke, M.L., 2003. Can flat-ramp-flat fault geometry be inferred from fold shape? A comparison of kinematic and mechanical models. Journal of Structural Geology 25, 2023-2034.

Sibson, R.H., 1986. Earthquakes and rock deformation in crustal fault zones. Annual Review of Earth and Planetary Sciences 14, 149-175.

Sibson, R.H., 2001. Seismogenic framework for hydrothermal transport and ore deposition. Reviews in Economic Geology 14, 25-50.

Strayer, L.M., Suppe, J., 2002. Out-of-plane motion of a thrust sheet during along-strike propagation of a thrust ramp: a distinct-element approach. Journal of Structural Geology 24, 637-650.

Suppe, J., 1983. Geometry and kinematics of fault-bend folding. American Journal of Science 283, 684-721.

Suppe, J., Medwedeff, D.A., 1990. Geometry and kinematics of faultpropagation folding. Ecologae Helvetiae 83, 409-454.

Thomas, A.L., 1994. POLY3D: a three-dimensional, polygonal element, displacement discontinuity boundary element computer program with applications to fractures, faults, and cavities in the earth's crust. Unpublished MS thesis, Stanford University, CA.

Wright, T.O., Platt, L.B., 1982. Pressure solution and cleavage in the Martinsburg Shale. American Journal of Science 282, 122-135. 